San Jose State University

SJSU ScholarWorks

Master's Theses

Master's Theses and Graduate Research

1993

\title{
The relationship between health concepts and health promotion behaviors in college students
}

Brenda C. Laird

San Jose State University

Follow this and additional works at: https://scholarworks.sjsu.edu/etd_theses

\section{Recommended Citation}

Laird, Brenda C., "The relationship between health concepts and health promotion behaviors in college students" (1993). Master's Theses. 692.

DOI: https://doi.org/10.31979/etd.cvr7-799s

https://scholarworks.sjsu.edu/etd_theses/692

This Thesis is brought to you for free and open access by the Master's Theses and Graduate Research at SJSU ScholarWorks. It has been accepted for inclusion in Master's Theses by an authorized administrator of SJSU ScholarWorks. For more information, please contact scholarworks@sjsu.edu. 


\section{INFORMATION TO USERS}

This manuscript has been reproduced from the microfilm master. UMI films the text directly from the original or copy submitted. Thus, some thesis and dissertation copies are in typewriter face, while others may be from any type of computer printer.

The quality of this reproduction is dependent upon the quality of the copy submitted. Broken or indistinct print, colored or poor quality illustrations and photographs, print bleedthrough, substandard margins, and improper alignment can adversely affect reproduction.

In the unlikely event that the author did not send UMI a complete manuscript and there are missing pages, these will be noted. Also, if unauthorized copyright material had to be removed, a note will indicate the deletion.

Oversize materials (e.g., maps, drawings, charts) are reproduced by sectioning the original, beginning at the upper left-hand corner and continuing from left to right in equal sections with small overlaps. Each original is also photographed in one exposure and is included in reduced form at the back of the book.

Photographs included in the original manuscript have been reproduced xerographically in this copy. Higher quality 6 " $\times 9$ " black and white photographic prints are available for any photographs or illustrations appearing in this copy for an additional charge. Contact UMI directly to order.

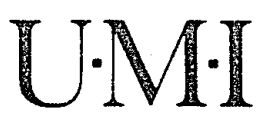

University Microfilms International

A Bell \& Howell Information Company 

Order Number 1356475

The relationship between health concepts and health promotion behaviors in college students

Laird, Brenda Carol, M.S.

San Jose State University, 1993 

THE RELATIONSHIP BETWEEN HEALTH CONCEPTS AND HEALTH PROMOTION BEHAVIORS IN COLLEGE STUDENTS

\author{
A Thesis \\ Presented to \\ The Faculty of the school of Nursing \\ San Jose State University \\ In Partial Fulfillment \\ of the Requirements for the Degree \\ Master of Science
}

\author{
by \\ Brenda C. Laird \\ December, 1993
}


(C) 1993

Brenda Laird

ALL RIGHTS RESERVED 
APPROVED FOR THE SCHOOL OF NURSING

Clepbeth C. Dee, Edh RN (:

ELIZABETH O. DIETZ, ELD, RN, CS.

Hewing Leihnaris

MAURA TEIKMANIS, MS, RN.

Barbara Kavolane MS, RN

BARBARA NAVOLANIC, MS, RN.

APPROVED FOR THE UNIVERSITY

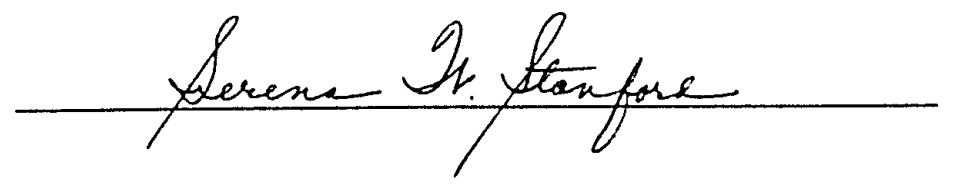




\author{
ABSTRACT \\ RELATIONSHIP BETWEEN HEALTH CONCEPTS AND HEALTH \\ PROMOTING LIEESTYLE BEHAVIORS AMONG COMMUNITY \\ COLLEGE STUDENTS \\ by Brenda C. Laird
}

The relationship between health concepts (independent variables) and health promoting behaviors (dependent variables) among college students at a small Northern California community college were identified. Using descriptive survey design, data were collected from 70 students who utilized the student health center during the data collection period. Laffrey's Health Conception Scale and Pender's Health Promotion Lifestyle Profile were used for data collection.

Data were described using percentages for the uncontrolled variables. Mean and standard deviation were used to describe the group responses to the dependent and independent variables. Spearman's rho correlation was done on variables to determine if relationships existed between health concepts and health promoting behaviors.

The findings indicated a weak relationship between the variables. The differences in means showed no statistically significant relationships. Conclusions indicated that although students had positive health concepts, they did not necessarily engage in health promoting behaviors. 


\section{Acknowledgements}

I would like to warmly thank my family who have been patient, loving, and supportive throughout the process of me attending graduate school, and who provided welcomed diversions.

Special appreciation to Dr. Elizabeth Dietz whose time, energy and input inspired me to finish this project. Additionally, thank you to Dr. Bobbye Gorenberg, Mahra Teikmanis, and Barbara Navolonic who spent many hours of their time helping me through the difficult process of thesis to graduation.

I hope I can move into nursing education to impart some of the knowledge I have learned. 
TABLE OF CONTENTS

Page
List OF TABLES $\ldots \ldots \ldots \ldots \ldots \ldots \ldots \ldots \ldots \ldots \ldots \ldots \ldots \ldots \ldots$
Chapter

1. INTRODUCTION. .................... I

Statement of the Problem............... 3

Purpose of the study.................. 4

Research Question........................ 5

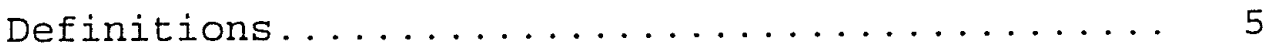

Significance of the study............... 7

2. CONCEPTUAL FRAMEWORK AND REVIEW OF RELATED

LITERATURE ................... 9

Conceptual Framework................... 10

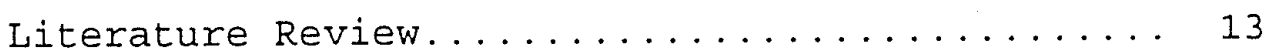

3. METHODOLOGY....................... 22

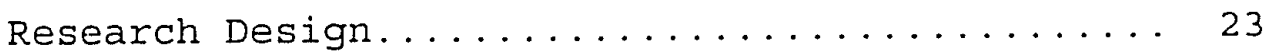

Subjects/setting.................... 24

Human Subjects Approval............... 26

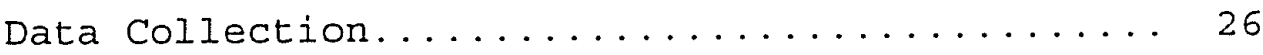

Instruments.................... 27

Analysis Procedures................... 31

4. FINDINGS AND INTERPRETATIONS ............ 34

Description of the sample.............. 34

Data Collection Procedures............... 38

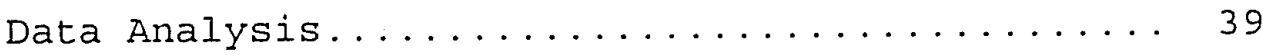


5. DISCUSSION....................... 44

Summary of study................... 44

Scope of the study................... 45

Assumptions of the study.............. 47

Limitations of the study.............. 47

Conclusions...................... 48

Recommendations.................... 51

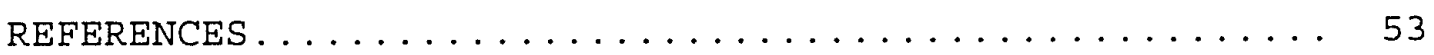

APPENDICES

A. Permission from SJSU Human Subjects.......... 62

B. Permission to Conduct Study............... 64

C. Laffrey Health Conception Scale

Instrument and Permission............ 66

D. Health Promoting Lifestyle Profile

Instrument and Permission. . . . . . . . 70

E. Student Demographic Profile for

Nursing Research Paper............... 75

F. Participant Cover Letter/Consent Form........ 77 


\section{LIST OF TABLES}

Table

1 Summary of student demographic profile..... 35

2 Data analysis of reactions to health concepts................... 40

3 Data analysis of reactions to health promoting behaviors.............. 40

4 Summary of intercorrelations between variables of LHCS and HPLP.......... 42 


\section{Chapter 1}

\section{INTRODUCTION}

"College life has offered various experiences that can promote health or increase the incidence of behaviors that have placed students at risk for poor health" (Jones, Harel, \& Levinson, 1992, p. 43). Traditionally, most college students have been young adults in a period of transition from adolescence to adulthood. However, many of the 12 million college students now enrolled in the 3253 community colleges and universities in the United States have been older adults and foreign students (Zapka \& Love, 1985). In California, community colleges have served the largest number of students enrolled in higher education, and have student populations diverse in age, ethnicity, socioeconomic status, and preparation for higher education (Health Services Association of California Community Colleges, 1992).

Health concerns have been at the forefront of the American health agenda for America to be healthy by the year 2000, according to Sharp (1991). Enhancing the educational process by modifying or removing health related barriers to learning, promoting optimal wellness, enabling students to make informed decisions about their health concerns, and empowering individuals to be self-directed and informed consumers of health services has been the 
purpose of college health nursing (American Nurses Association [ANA], 1990).

The Surgeon General's report in 1979 identified activities which individuals and communities can use to promote healthy lifestyles that included improved nutrition, exercise and fitness, smoking cessation, stress control, and reducing misuse of alcohol and drugs (U.S. Department of Health, Education, and Welfare, Public Health Service [USDHEW, PHS], 1990). Many health promoting activities and behaviors, such as self-actualization (optimistic outlook on life), health responsibility (general competence in caring for one's own health), exercise (engaged in physical or recreational activity), nutritional practices, interpersonnal support (relationships with others), and stress management have been directed at school-age children, working adults, and the elderly in institutional programs.

College health education programs have been a combination of activities designed to provide motivational, organizational, and environmental support for behavior conducive to the health needs of the students (Green, Kreuter \& Deeds, 1980). There has still been a need to address the health of all people, including college students, to achieve the desired goal of a healthy America (American College Health Association [ACHA], 1992). 
Statement of the Problem

The college years for any student have been viewed as a period of psychologic and social development, according to Zapka \& Love (1985). This period in a student's life, dedicated to learning and exploration, has been fertile territory for questioning and challenging social policies and institutions. It has been a time when students were under a great deal of stress and were at risk for accidents and illness (Zapka \& Love, 1985). College life presented new demands on students that were associated with a different structure to daily life for both traditional and non-traditional students (Jones, Harel, \& Levinson, 1992). Many individuals have moved away from home and have taken responsibility for their own health for the first time (Zapka \& Love, 1985).

The illness and accident profiles of college students suggested there have been major health areas for health professionals to provide health protection and health promoting activities (Zapka \& Love, 1985). Important issues, such as drug and alcohol use, nutrition, physical fitness, and stress have been clearly related to life style and personal behavior decisions (Zapka \& Love, 1985).

There has been a need to determine how students define their health, and have engaged in the health behaviors of stress management, proper nutrition, interpersonal support, exercise, health responsibility, and self actualization. 
Sharp (1991) stated it has been appropriate to focus on health promoting behaviors in college students as there has been an agenda in America to improve the health of all people.

\section{Purpose of the Study}

The purpose of this study was to determine the degree that selected components derived from Pender's (1987) Health Promotion Model (HPM) explained engaging in health promoting behaviors in a sample of community college students at a small rural Northern California community college. Two components of the HPM were chosen for study. First, the cognitive perception of the definition of health was measured using Laffrey's Health Conception Scale (LHCS). The second component measured was the health promoting practices of stress management, nutrition, interpersonal support, exercise, self-actualization, and health responsibility using Pender's Health Promotion Lifestyle profile (HPLP). This study was a replication of an unpublished study that used Pender's Health Promotion Model as the conceptual framework and was done at the University of South Carolina by Gwen Felton, PhD., and Mary Ann Parsons, PhD. (Sachs, 1991).

Felton and Parsons examined the value and definition of health, problem solving, and their impact on the health behaviors of stress management, nutrition, interpersonal support, exercise, self actualization, and health 
responsibility among unmarried college students (Sachs, 1991). Felton and Parsons reported that group participation was related to positive health behaviors, however, neither health value nor definition of health contributed to health promoting behavior in their large sample of unmarried students (Sachs, 1991).

Research Question

What was the relationship between reported health concepts and health promotive behaviors in college students?

\section{Definitions}

1. Health: Health is defined as "the positive state of full functioning in relation to one's capabilities and Iife-style, not merely the absence of disease or infirmity" (ANA, 1990). Health signifies the idea of positive ongoing experiences of humans throughout a lifespan within the environment (Pender, 1987).

2. Health promotion: Health promotion is the process to help or encourage humans to exist and flourish within the environment using behaviors directed towards increasing the level of well being and actualizing their health potential (Pender, 1987).

3. Health promoting behaviors: Health promoting behaviors are those behaviors that any person, in any group, initiates to maintain or increase their physical or mental fulfillment. Routine exercise, proper nutrition, 
stress management, interpersonal support systems, and leisure activities are all examples of health promoting behaviors. The individual's motive to initiate or sustain a behavior distinguishes health promotion from health protection or disease prevention (Pender, 1987; Palank, 1991). People move from decision making to taking action (Pender, 1987).

4. Health prevention: Health prevention is the process that is meant to decrease threats or insults to the health of an individual, a family, or a community (Pender, 1987).

5. Health concepts: Health concepts are defined as "a person's views on the definition of their health which have influenced the practice of common health promoting activities" (Laffrey, 1985).

6. Non-traditional students: Non-traditional students are defined as "adult learners of any gender or age" (Lappin, 1992). Prior to 1960, non-traditional students were defined as adult female learners. However, since 1960 non-traditional students have been comprised of various groups of people. These people included the displaced homemaker, the empty nest mother, the blue-collar wife, the single parent, the career woman or man with or without children who required career advancement training or career change training, students in the 55-75 age bracket, the foreign student, the commuter student, the minority student, and the first generation college student of 
immigrant families (Lappin, 1992).

7. Traditional students: Traditional students are those people between 18-25 years of age who lived in residential housing and were supported by parents. The image of the traditional student was that the population was homogeneous and primarily white males who completed college in 4 years (Lappin, 1992).

\section{Significance of the Study}

College students, of all ages, often conceal fear of failure, loneliness, family problems, and other concerns in vague physical complaints (Peplau, 1986). Lifestyle choices made to cope with stress can put these people at risk for substance abuse, suicide, pregnancy, sexually transmitted diseases, and eating disorders (Peplau, 1986). Traditional and non-traditional college students often have overwhelming adjustment needs to the changing lifestyle they have experienced causing them to have added risk for accident injury, alcoholism, smoking dependency, and drug addiction (ANA, 1990).

Greater risk taking occurs in all college students and has been characterized by judgemental errors, ambivalance to life, aggressiveness, and misuse of drugs, alcohol, and tobacco (USDHEW, 1990; Wallace, Patrick, Parcel, \& Igoe, 1992). Community colleges and commuter campuses face additional challenges. For example, older students face the responsibility of families and jobs as well as the 
burden of being a student (ANA, 1990).

In 1985, the ACHA joined the national effort for a healthy America, with the formation of the Task Force on National Health objectives in Higher Education. The task force was charged with reviewing how college students were meeting pertinent national health objectives. All regions of America made recommendations that were relevant to student populations of higher education. The formation of Healthy Campus 2000, created by the ACHA, brought a spirit of optimism and challenged individuals at all colleges to improve the health of students (ACHA, 1992).

In summary, this chapter discussed the problems students have in college, identified the purpose of the study, defined the terms used in this study, discussed the significance of the research, and asked the research question "what was the relationship between health concepts and health promotive behaviors in college students?" 


\section{Chapter 2}

CONCEPTUAL FRAMEWORK AND REVIEW OF LITERATURE

In the past decade, there have been vigorous efforts to promote healthy lifestyles among college students, and eliminate unhealthy lifestyle behaviors (American College Health Association [ACHA], 1992). This chapter discussed the conceptual framework of the Health Promotion Model (HPM) and summarized a literature review of: (a) the historical account of college health and health promotion, (b) strategies and advocacy for health promoting behavior practices, (c) application of the Health Promotion Model (HPM), and (d) the various aspects of health promoting behavior activities reported in previous research.

The Health Promotion Model, developed by Pender (1987), was meant to explain lifestyle patterns or specific health promoting behaviors. The nature of health promotion has been multidimensional and the behaviors engaged in have been those that would increase an individual's level of well-being, personal fulfillment, and self-actualization rather than those that react to the threat of illness (Palank, 1991). According to Pender (1987), individuals moved reciprocally between decision-making and taking action to improve their health. The use of a health promoting lifestyle profile along with a health conception scale fit into Pender's Health Promoting Behavior Model. 
The Health Promoting Model provided a useful framework for explaining health behaviors among college students.

\section{Conceptual Framework}

Pender (1987) formulated the Health Promotion Model

that was derived from social cognitive theory in which cognition, actions, affect, and environmental events were proposed as operating interactively in determining behavior and included determinants of health promoting behaviors. The HPM model was meant to explain and predict the factors that motivate individuals to engage in health promoting behaviors. Although negative states of illness and disease motivated individuals to engage in health protecting behaviors, individuals who engaged in health promoting behaviors had a desire for personal growth, improved quality of life, and expression of human growth, according to Pender (1987). Health promoting behaviors have been directed toward maintaining or improving the person's level of well being, personal fulfillment, and self actualization and away from reacting to a threat of illness (Pender, 1987).

Within the HPM, the primary predicators of health promoting behaviors consisted of 3 components. The first component of the HPM consisted of cognitive or perceptual factors that exert a direct influence on the individual and act as the primary motivational mechanism for the individual to initiate, aquire, and maintain health 
promoting behaviors (Pender, 1987). The cognitive factors that directly influenced the likelihood of health promoting actions included: (a) the importance of health, (b) self efficacy, (c) perceptions of health, (d) individual definition of health, (e) current health status, and (f) perceived benefits or barriers to health promoting behaviors (Fluery, 1992; Pender, 1987).

The second component of the HPM consisted of modifying factors that indirectly affect health promoting behaviors by their impact on cognitive mechanisms. The modifying factors provided a foundation to enable or constrain the person's decision to engage in health promoting behaviors. The modifying factors included: (a) demographic characteristics such as age, sex, education, and ethnicity, (b) biologic characteristics including body composition and body weight, (c) interpersonal influences such as expectations of family, friends and social norms, (d) situational events such as health promoting options within the environment, and (e) behavior variables including prior experiences with health actions (Pender, 1987).

The third component of the HPM was the likelihood of engaging in health promoting action as described by "cues to action" that have a direct influence on whether or not the individual was directed toward enhancing or maintaining well being (Fluery, 1992; Pender, 1987). The cues to 
action depended on activating cues of internal or external origin that trigger a health related behavior. The internal or external cues derived by the individual's experience moved them from the decision-making phase to the action phase. The intensity of the cues may have depended on the individuals readiness to act (Palank, 1991). Factors influencing the likelihood of taking action were awareness of potential for growth, advice from others and mass media. Factors for not taking health promoting action were inconvenience, cost, unavailability, and extent of life change required (Pender, 1987).

The HPM has been used to explain and predict patterns of health promoting lifestyle activities that included: (a) self actualization, (b) exercise, (c) stress management, (d) interpersonal support, and (e) health responsibility (Fleury, 1992). According to HPM, the likelihood that a health promoting behavior or lifestyle will occur was determined by combining individual cognitive factors, modifying factors, and cues to action (Palank, 1991).

The health promoting behavior themes are different from disease prevention behavior themes (to keep from occurring) by encouraging individuals to be engaged in health promoting activities to improve their well being rather than only engaging in behaviors that were meant to decrease threats or insults to health (Pender, 1987). 
Smith (1990) wrote about the practical application of the health promoting model stating that: (a) health promotion is more than and different from disease prevention, (b) the whole person is encompassed in health promotion, (c) the environment is involved in the changing relationships of health promotion, (d) the process of health promotion involves an intense interhuman process, and (e) the person subjectively evaluates their own health. HPM themes delimited health promotion by presenting the health promoting model as holistic, rational, interpersonal, and person oriented (Smith, 1990). Health promotion focused on five specific strategy targets that included: (1) cessation of smoking, (2) nutrition, (3) independence from alcohol and drugs, (4) physical fitness and exercise, and (5) stress management (U.S. Department of Health, Education, and Welfare, Public Health Service [USDHEW, PHS ], 1990).

\section{Literature Review}

This literature review included: (a) the historical account of college health and health promotion programs, (b) strategies and advocacy for health promoting behavior practices, (c) application of the Health Promotion Model (HPM), and (d) the various themes of health promoting behavior activities reported among the general population and college students in previous research. A review of current literature revealed little information regarding 
health promoting behaviors engaged in by college students.

\section{Historical Account of College Health Programs}

Health education and health care have been components of college health services since 1859, when Amherst College in Massachusetts became the first American college to employ a physician as professor of hygiene to provide student health services, according to Boynton (1962). At that time in history, health care was associated with the goal of screening for communicable disease (Wallace, Patrick, Parcel, \& Igoe, 1992, p. ix).

Profound social changes in the 1960's helped mobilize both student and college health professionals to respond to the needed changes in traditional college health services (Klotz, 1974). Consumer involvement activities in the 1970 's and 1980's toward college health services included the undertaking of health education projects and policy making activities. College students proved to be strong advocates of health education. An example of student advocacy occurred at a small rural Northern California community college in 1990 when the students recommended a health center be opened on campus. The college board of governors approved the students request and in the fall of 1991 a student health center was opened to all students (L. Simas, personal communication, September, 1991).

Strategies and Advocacy for Health Behavior Practices

Over the years colleges and universities have 
addressed the need to provide health services to their students. College health programs have evolved from providing basic preventive health care and health education to providing expanded primary health care services and health promotion information and activities to all students (Wallace, Patrick, Parcel, \& Igoe, 1992, p. ix).

Lauzon (1977) stated when advocating for health promoting practice one should be concerned with all influences in one's life. The interaction of all life forces (reinforcing, competing, contradictory impact of education messages, media advertising, availability of products and services, laws and regulations, and environment) need to be considered in health promoting activities (Lauzon, 1977).

The Surgeon General's report in 1979 brought to light the need to improve the health of all Americans. Scientific research had shown that many degenerative diseases were preventable (USDHEW, PHS, 1990). The health care community's knowledge base for encouraging health promoting behaviors has improved since the 1979 Surgeon General's Report, "Healthy People", and its recent update, "Healthy Goals for the Year 2000" (Patrick, 1992). In 1990, the American College Health Association (ACHA) adopted the objectives from Healthy People 2000 for health promotion activities on college campuses (Patrick, 1992). These objectives for health promoting behaviors included: 
(a) increasing physical fitness and exercise, (b) improving nutrition, (c) management of stress, (d) cessation of smoking, and (e) reducing alcohol and drug use for all college students (ACHA, 1992).

Currently, the major efforts at health promoting and health preventing practices from the health care community have focused on the person and the family. A variety of strategies have been employed by health professionals to guide health promoting activities, such as health risk appraisals, lifestyle modifications, health education, stress management, and anticipatory guidance (Doerr \& Hutchins, 1981; Gale \& Clark, 1986; Redman, 1984; Scandrett \& Uecker, 1985; Standhope \& Lancaster, 1984).

Application of the Health Promotion Model

Health promotion and early detection of disease through risk assessment appraisal became a significant aspect of health care in the United States (Allan, 1987). Healthy choices of individuals at an early age have lead to a life free of chronic disabling diseases and conditions. Additionally, healthy choices by individuals have helped young adults carry future responsibility for building healthy families, worksites, social norms, and political structures essential to a process that has contributed to improved health for all (Sloane \& Zimmer, 1992).

Published research for the HPM has been applied to groups of people such as: (a) midlife and employed women 
(Duffy, 1993), (b) cancer patients (Frank-Stromberg, Pender, Walker, \& Sechrist, 1990), (c) blue collar workers (Weitzel, 1989), (d) health fair attendees (Waller, Crow, Sands, \& Becker, 1988), (e) older adults (Walker, Volkan, Sechrist, \& Pender, 1988), (f) the elderly (Speake, 1987), and (g) farm workers (Kerr \& Ritchey, 1990). One recent study determining risk taking behaviors and other correlates of seat belt use was done among university students to determine seat belt use when riding or driving in a car (Oleckno \& Blacconiere, 1990). Although limited, Duffy (1993) concluded that most research studies reported that the evidence for the relationship between health practices and health status was often weak, and that most studies examined only a few health habits.

Pender, Walker, Sechrist, and Frank-Stromberg (1990) found that the health promotion activities of nutrition, exercise, self-actualization, interpersonal support, health responsibility, and stress management related significantly to better health among employees enrolled in a employer sponsored health promotion program. The unpublished Felton and Parsons' study reported that problem solving explained $19 \%$ of the health promoting behavior, with $9 \%$ explained by the modifying factors of demographic and biological characteristics. Group participation was related to positive health behaviors. Neither health value nor health definition contributed to health promoting behavior in the 
sample of unmarried college students in the Southeastern United States (Sachs, 1991).

The HPM has received considerable empirical support. In her review of health promotive behavior determinants, Palank (1991) concluded that "the exact impact of the various variables on singular behaviors is far from conclusive. The difficulty in concluding which variables of the HPM were most critical was perhaps due to the variety of definitions, different theoretical approaches, and research methods" (p. 827).

Themes of health promoting behavior activities

The health promoting behavior activities that have been researched are discussed in the remaining section of this chapter. These activities, which the U.S. Government (1990) identified for health promotion action, included exercise, nutrition, stress and interpersonal conflict, and the use of tobacco, alcohol, and drugs.

Exercise alone has resulted in increased range of mobility, self-esteem, vitality, cardio-vascular endurance, and improved affect in both young and older individuals (Paillard \& Nowak, 1985; Pender, 1987; Halfman \& Hojacki, 1981). A study done by Volden, Langemo, Adamson, and Oechsle (1990) using the Health Promotion Lifestyle Profile and Laffrey's Health Conception Scale within the framework of the Health Promotion Model concluded exercisers scored higher than nonexercisers in a large group of rural-urban 
adults.

In balance with exercise, diet and nutrition have been found to affect general health in a direct, positive and cumulative way (DuBrey, 1982; Pender, 1987; Volden, Langemo, Adamson, \& Oechsle, 1990). According to Kurtzman and Yager (1992), the use of alcohol or drugs, financial concerns, and interpersonal conflict may have been causes for poor nutrition. Research has shown that eating disorders among college students increased over the past 10 years, and may have been due to stressors inherent in the college environment, according to whitaker (1989).

Stress affects all the body's systems. Selye (1977) wrote "the optimal stress level for any individual was the point on the stress continuum where performance and health were maximized" (p.1). It has been well known that academic stresses vary considerably over the course of an academic year. Acquiring skills needed to deal with stress in a positive way minimizes harmful effects of stress (Pender, 1987; Volden, Langemo, Adamson, \& Oechsle, 1990).

Experts have concluded that there were multiple causes, such as psychosocial, pharmacologic, and physiologic forces, for individuals to smoke tobacco. College student peer pressure influences, alcohol, and other drug use have been associated with the onset of tobacco use (Lovato, 1992). Studies have shown people were healthier, lived longer and freer from disease when 
tobacco, alcohol, and drugs were not used (USDHEW, PHS, 1990).

Alcohol use and abuses on college campuses have been described in many studies. The estimations have been that $90 \%$ of college students drink at one time or another, and have often ingested large amounts of alcohol (Burns, 1992). From an epidemiologic perspective, according to Burns (1992), there have been two major risks to college students from overuse of alcohol. The first category, acute risks, came from alcohol consumption and included alcohol poisoning, accidents, injuries, missed obligations, sexually transmitted diseases, regretted sex, rape, and damaged reputation. The second category, chronic risks, have included long term consequences which resulted in damaged to the vital organs of the body, and produced patterns of behavior that damage social relationships, work obligations, and lead to early death (Burns, 1992).

Many researchers believed encouraging health promoting behaviors in the above described areas has advanced the goals discussed in creating a healthy campus. The social movement towards self-care and wellness programs have been guiding people from "cure" to "promotion" (Palank, 1991). The focus of research on health behavior has been directed primarily at exploring the various perceptions on the likehood of behavior and the impact of each health promoting behavior variable in a personal lifestyle 
(Palank, 1991).

The status of student health services in many colleges has improved over the past decade, according to Patrick (1992). Integration of health promoting behavior programs in student health services will be essential if the highest quality of college campus life is to be attained (Patrick, 1992). The ACHA, colleges, and universities have begun working on means of delivering the targeted health promoting objectives to students (Delene, 1992). College health nurses, in their unique position, have the opportunity to integrate and allow students to understand the mind, body, and spirit relationship. College health nurses have the opportunity to promote the health of all students utilizing health promoting programs directed at the college community.

In summary, this chapter presented (a) a summary of the Health Promotion Model that was used as the conceptual Eramework for this study, and (b) a literature review of health promotion behaviors that included studies pertaining to health behaviors of college students. 
Chapter 3

METHODOLOGY

The purpose of this study was to explore the relationship between health concepts and health promoting behaviors among college students at a small rural Northern California community college. The research study was a replication of an unpublished study done at the University of South Carolina by Gwen Felton, PhD., and Mary Ann Parsons, PhD. (Sachs, 1991). Felton and Parsons surveyed 593 unmarried college students in the Southeastern United States using Pender's Health Promotion Model as the conceptual framework. Students were surveyed over a two month period using the Health Value Survey (wallston), Health Conception Scale (Laffrey), Problem Solving Inventory (Heppner), and Health Promoting Lifestyle Profile (Walker, Sechrist, \& Pender). Data were analyzed by "examining the relationship to cognitive and modifying factors (demographic and biological characteristics) and its ability to predict health promoting behaviors" (Sachs, 1991, p.4). This study did not address the Health Promotion Model's components of modifying factors or cues to action.

This chapter discusses how subjects were obtained for the research, what setting was used, and how data was collected. Additionally, the chapter discusses what 
instruments were used to collect data, human subject approval, and what analysis procedures were utilized.

Research Design

Pender's Health Promotion Model was selected as the framework for this study. Pender (1987) stated the "model was based on a synthesis of research findings from studies of health promotion and wellness behavior" (p. 57). The non-experimental research design of this study was descriptive and exploratory in nature as the characteristics of both survey and correlational studies were utilized. According to LoBiondo-Wood and Haber (1990), survey studies collect detailed descriptions of existing phenomena and use the data to justify and assess or improve current conditions and practices. Correlational studies endeavor to trace interrelationships between variables that provide a deeper insight into the phenomenon of interest. The advantage of using a survey design were that a great deal of information was collected in a short period of time. The advantages of a correlation design were two-fold: (1) a potential foundation for practical application in a clinical setting was provided, and (2) a potential foundation for future, more rigorous research studies was provided (LoBiondo-Wood \& Haber, 1990).

Two Likert surveys were used to collect and evaluate data on personal health conceptions and health promoting behaviors engaged in by a sample population of 70 students 
at a small rural Northern California community college. A search for more accurate information about the health attitudes and behaviors of college students was sought to determine the unique health needs of the students. The self-reported survey questionnaires chosen for the study were designed to help students assess their perceptions about their health status which could help them identify concepts important to their health.

The independent variables of the health conception scales and the dependent variables of the health promoting scales were compared for group relationships. In addition, the uncontrolled variables of student demographics were identified.

\section{Subjects/setting}

To insure maximal participation and obtain the needed minimal sample size of 70 participants, individuals were approached face-to-face in the student health center waiting room to seek volunteers. To determine the needed size of a random sample chosen from the target population, the recommendations of Issac and Michael (1985) were applied to obtain a representative sample from the student population. Issac and Michael (1985) provided a table for determining the needed sample size of a randomly chosen sample from a given finite population. The recommendation was that if the finite population was 85 , then the recommended sample size of participants in the research 
study needed to be 70 persons.

of the 85 students who utilized the health center during the data collection period, the 70 students who agreed to participate in the study ranged in age from 16 to 50 years. The number of 70 participants for the sample size allowed that the sample proportion $\mathrm{p}$ would be within .05 of the population proportion with a 95 percent level of confidence when analyzing the data (Issac \& Michael, 1985).

At the beginning of each semester, all students were required to pay a fee to utilize the health services on campus. All students were informed of the health center services in printed material, such as class schedules, the college newspaper, and a weekly student letter. In addition, each student received a student health center brochure as part of their registration packet at the beginning of the semester. Thus, the participating students involved in the study had equal access to the student health center during the data collection period, as did students who did not participate in the study.

College students were chosen for the research because more accurate information was desired for identifying student health needs and for planning appropriate health promoting behavior programs at the participating campus. There was no compensation to the students for participating in the study. Participation in the study may have helped the student to evaluate any changes that occured in health 
concepts and the health promoting behaviors which they utilized for themselves. No known anticipated risks to the students were expected as all information was kept confidential, and the results were completely anonymous. Human Subjects Approval

Permission from Human Subjects in Research was granted from San Jose State University Graduate Studies (Appendix A). The Dean of Academic Services at the small rural Northern California cornmunity college granted permission to conduct this study (Appendix B). Written permission to use the Laffrey Health Conception Scale (LHCS) was obtained from the author (Appendix C). Written permission to use the Health Promoting Lifestyle Profile (HPLP) was obtained from the authors (Appendix D). Data Collection

The data were collected over a two week period in December of 1992 prior to the end of the semester. Students entering the student health center for health services at the college were asked to participate in the study.

A cover letter (Appendix F) explaining the purpose of the study and assuring participants confidentiality of their responses was given to the 70 participating students together with the Health Promoting Lifestyle Profile survey, the Laffrey Health Conception Scale survey, and a demographic profile data sheet created by this investigator 
(Appendix E). Return of the completed materials implied consent by the student for participation in the study.

\section{Instruments}

Two health surveys and a demographic profile data sheet were used to collect the data.

1. The Laffrey Health Conception Scale (LHCS)

(Appendix C) was developed to measure the individual's perception or definition of health to which an individual subscribes (Laffrey, 1986). The LHCS, based on the description of 4 ideas of health included the following subscales: (1) clinical health (absence of disease, illness, or symptoms), (2) role performance or functional health (capacity to carry out usual roles in a satisfactory manner), (3) adaptive health (ability to adjust to life situations), and (4) eudaimonistic health (exuberant well being).

The LHCS had 28 short, descriptive statements about the nature or idea of health, arranged in a Likert format, ranging from 1 (strongly disagree), 2 (moderately disagree), 3 (disagree), 4 (agree), 5 (moderately agree), to 6 (strongly agree). The overall score and the subscale scores indicated the strength of total health conception, allowing for comparisons across groups of individuals. An individual's score was obtained for each subscale of health conception by summing the scores of the items and then summing all of the items for the total score (Laffrey, 
1986). The use of means were utilized to allow for meaningful comparison with the Health Promoting Lifestyle Profile.

The LHCS survey had internal consistency with a standardized item alpha coefficient of .88 . The 4 subscales had standardized item alpha coefficient ranging from .86 to .88. Relationships among the 4 subscales showed a low score suggesting each subscale represented a distinct dimension of health conception (Laffrey, 1986).

Construct validity of LHCS was established by Laffrey (1986) through factor analysis of the 28 items loading their respective subscales at a level of .45 or greater. The scale alpha coefficient for internal consistency was .88. The 4 subscales together explained $62 \%$ of the variance of the 28 items measured (Laffrey, 1986). Testretest reliability after 1 week was .84 (Laffrey, 1986).

2. The Health Promoting Lifestyle Profile (HPLP) (Appendix D) was developed to measure an individual's response of self-initiated health promoting activites and perceptions which the individual regularly engage in to maintain or enhance their well-being (walker, Sechrist, \& Pender, 1987). The HPLP based on the description of 6 subscales for health promoting lifestyle behaviors included the following dimensions: (1) self actualization (the capacity to become whatever the individual believed capable of being), (2) health responsiblity (taking responsibility 
for one's own health), (3) exercise (physical or recreational activity), (4) nutrition (nutritional practices), (5) stress management, and (6) interpersonal support (relationships with others). The HPLP survey was designed to enable researchers to investigate patterns and determinants of a health promoting lifestyle, as well as the effects of interventions to alter lifestyle behaviors (Walker, Sechrist, \& Pender, 1987).

The HPLP survey contained 48 descriptive statements about health promoting lifestlye behaviors of individuals, arranged as a Likert scale format, ranging from 1 (never), 2 (sometimes), 3 (often), to 4 (routinely). An individual's score was obtained for each subscale of health promoting behaviors by summing the scores of the items and then summing for the total score. The use of means rather than sums of the scales items was recommended by walker, Sechrist, and Pender (1987) to allow for meaningful comparisons of scores across subscales.

The HPLP survey had a high internal consistency with a standardized item alpha coefficient of .94. The 6 subscales had standardized item alpha coefficient ranging from .76 to .91. Relationships among the 6 subscales showed a low to moderate score suggesting each subscale represented a distinct dimension related to other dimensions of health promoting behaviors without being redundant (walker, Sechrist, \& Pender, 1987). 
Construct validity of the HPLP subscales was supported by factor analysis with all items loading their respective subscales at a level of .35 or higher. The 6 subscales explained $47.1 \%$ of variance of the 48 items measure (Walker, Sechrist, \& Pender, 1987). The test-retest $r$ was .93 over a two week period (Walker, Sechrist, \& Pender, 1987).

3. A student Demographic Profile data sheet was developed for this study by the investigator. The demographic profile was used to present percentile values of the demographic variables of age, gender, ethnic/racial background, student status, marital status, employment status, and medical insurance status.

The LHCS contained questions about the participant's idea or definition of health, and the HPLP contained questions regarding behaviors engaged in by participants to promote their health. The student demographic profile data sheet collected personal information regarding the student. Contruct validity was established by 7 college staff members and students pretesting the survey packet for an understanding of the written questions and to determine readability and comprehension of the questions. The average time for participants to complete the questionnaires was 10 minutes. The participants stated they understood the questions and did not have difficulty completing the surveys. Therefore, following the pretest, 
no changes were made to the packet given to the sample population.

\section{Analysis Procedures}

The research was a descriptive study that involved organizing, tabulating, and summarizing data for the purpose of describing the sample measured. Nonparametric measures were used to compute the sample data as the assumption was that nonparametric methods provided test statistics that were not dependent on the distribution of a parent population being sampled or for unspecified distributions (Johnson, 1988). With descriptive statistics, no attempt was made to infer the characteristics of individuals that were not measured. The data were analyzed as group information using Minitab, a statistical computer program (Ryan, Joiner, \& Ryan, 1992).

Inferential statistics of Wilcoxon matched-pair testing (a non-parametric measure) was utilized to measure the differences between means and standard deviation. Since the data were ordinal level, Spearman's rho was used to measure the correlation coefficient (Johnson, 1988) to determine whether there was a relationship between health concepts and health promoting behaviors among college students.

The uncontrolled demographic variables were described in percentile ranks only, as the study was looking at group data. Standard deviation, the most stable of the measures 
of variability (Johnson, 1988), was used to present accurate indications of the spread of distribution of the independent and dependent variables of the two surveys the participants completed. Thus, central tendencies were described in means and standard deviation. Relationships between the independent and dependent variables were first measured for differences in means and then tabulated using correlation coefficient. Correlation was a statistic that standardized the measure of dependency and allowed for comparison of the relative strength of dependency for different sets of data (Johnson, 1988).

For this study the two groups of variables were the health concepts and health behaviors. The use of correlation coefficient measured the strength of the relationships between two variables from an ordinal scale. According to Jaeger (1990, p. 368) correlation coefficient statistics want to answer questions such as: (a) what is the correlation between scores on the two tests (concepts and behaviors)? (b) if the score is known on one test (concepts), does that help in predicting the score on the second test (behaviors)? (c) does a person score high on the second test (behaviors) if they scored high on the first test (concepts)? and (d) can outcomes be predicted?

In summary, this chapter discussed the design and methodology of the descriptive research. The discussion included how subjects were obtained, what setting was used 
for the research, how human subject approval was obtained, how data were collected, and how data were analyzed. The chapter discussed which instruments were used to collect the data for the research and what analysis procedures were utilized to determine the results of the research. 


\section{Chapter 4}

\section{FINDINGS AND INTERPRETATIONS}

The purpose of this study was to explore the relationship between health concepts and health promoting behaviors among students at a small, rural Northern California community college. Health concepts were measured using Laffrey's Health Conception Scale (LHCS), and health promoting behaviors were measured using Walker, Sechrist, and Pender's Health Promoting Lifestyle Profile (HPLP). The study sample consisted of 70 college students.

The findings and interpretations are presented in this chapter. Analysis was done on the collected data using Minitab, a computer statistical program (Ryan, Joiner, \& Ryan, 1992). The reported findings were restricted to describing demographic data in percentiles and group data in means, standard deviation, and relationships among the subscales.

\section{Description of the Sample}

The demographic data (Table 1) illustrated that of the 70 participants, there were 30 male (43\%) and 40 female (57\%) participants. Ages ranged from 16-50 years; 15 $(21.4 \%)$ were under 21 years, 34 (48.6\%) were between 21-30 years, $12(17.1 \%)$ were between $31-40$ years, and 9 (12.9\%) were between 41-50 years. There were no participants over 50 years of age. 
Table 1

Summary of Student Demographic Profile

\begin{tabular}{|c|c|c|c|}
\hline Profile Item & $\mathrm{N}$ & $\underline{\mathrm{n}}$ & 高 \\
\hline Gender: Male & 70 & 30 & 43.0 \\
\hline Female & 70 & 40 & 57.0 \\
\hline Age: Under 21 years & 70 & 15 & 21.4 \\
\hline $21-30$ years & 70 & 34 & 48.6 \\
\hline $31-40$ years & 70 & 12 & 17.1 \\
\hline $41-50$ years & 70 & 09 & 12.9 \\
\hline \multicolumn{4}{|l|}{ student status: } \\
\hline Full-time (12+units) & 70 & 46 & 65.7 \\
\hline Part-time (1-11 units) & 70 & 24 & 34.3 \\
\hline \multicolumn{4}{|l|}{ Ethnic group/race: } \\
\hline Hispanic/Latino & 70 & 06 & 08.6 \\
\hline Black/African American & 70 & 11 & 15.7 \\
\hline American Indian/Alaskan & 70 & 01 & 01.4 \\
\hline Asian/Pacific Islander & 70 & 12 & 17.1 \\
\hline White & 70 & 34 & 48.6 \\
\hline Other (self-described) & 70 & 06 & 08.6 \\
\hline \multicolumn{4}{|l|}{ Marital status: } \\
\hline Single & 70 & 43 & 61.4 \\
\hline Married & 70 & 12 & 17.2 \\
\hline Divorced & 70 & 14 & 20.0 \\
\hline
\end{tabular}




\begin{tabular}{cccc}
\hline Profile Items & N & $\underline{n}$ & 兰 \\
\hline Separated & 70 & 01 & 01.4 \\
Employment staus: & & & \\
Full-time & 70 & 08 & 11.4 \\
Part-time & 70 & 34 & 48.6 \\
Unemployed & 70 & 27 & 38.6 \\
Retired & 70 & 01 & 01.4 \\
Medical insurance: & & & 28.6 \\
HMo & 70 & 20 & 17.1 \\
Military & 70 & 12 & 10.0 \\
Private & 70 & 07 & 15.7 \\
Medical/Medicare & 70 & 11 & 28.6 \\
No insurance & 70 & 20 & \\
\hline
\end{tabular}

There were $6(8.6 \%)$ Hispanic/Latino students, 11 (15.7\%) were Black/African American students, 1 ( $1.4 \%$ ) was an American Indian/Alaskan student, 12 (17.1\%) were Asian and Pacific Islander students, 34 (48.6\%) were White students, and $6(8.6 \%)$ were from other ethnic groups (self-described as African-Indian, Semitic, Black-Hispanic, Mexican, Spanish-American, and Multi-Ethnic). Forty-six $(65.7 \%)$ of the participants were full-time students, taking 12 or more units, whereas 24 (34.3\%) students were part-time, taking 1 to 11 units. 
At the time of the study, 43 (61.4\%) students were unmarried, 12 (17.2\%) students were married, 14 (20\%) students were divorced, and 1 ( $1.4 \%$ ) person was separated from their spouse. Eight (11.4\%) participants were employed full-time, $34(48.6 \%)$ students were employed part-time, $27(38.6 \%)$ students were unemployed, and 1 $(1.4 \%)$ was retired. Twenty $(28.6 \%)$ of the participants had medical insurance through a large group HMO, 12 (17.1\%) participants had medical coverage provided by the U.S. Government, 11 (15.7\%) participants had MediCal/Medicare coverage, whereas $20(28.6 \%)$ students had no health insurance.

At least half of the group was characterized as being in the age range from 21-30 years, White, full-time students, unmarried, employed, and women. By definition, the sample had characteristics of both traditional and non-traditional students. The group that did not have health insurance was consistent with current estimates gathered by other health professionals (Wallace, Patrick, Parcel, \& Igoe, 1992). The information from the participating campus regarding college trends for 1990-91 was female gender $56.9 \%$, White $48.6 \%$, and $40 \%$ between $21-30$ years (C. Jarrett, personal communication, september, 1992). Data from this study were similar to the study group at the small rural Northern California community college. 
Data Collection Procedures

The relationship of health promoting lifestyle behaviors and health concepts were determined by a comparison of the 4 subscales of the LHCS and the 6 subscales of the HPLP. The LHCS scores were computed by summing all 28 item responses for a total score, while each subscale contained items that were summed as follows:

(a) clinical health was computed from items 4, 5, 9, 11, 15,20 , and 25 ; (b) role performance/functional health was scored from items $3,5,10,17,21,24$, and 26;

(c) adaptive health consisted of items 2, 8, 13, 14, 19, 22 , and 27 being summed; and (d) eudaimonistic health (exuberant well being) was summed from items 1, 7, 12, 16, 18, 23, and 28 (see Appendix C).

HPLP scores were determined by summing the responses to all 48 item responses to obtain a total score, while the subscales were summed as follows: (a) self-actualization was computed by summing items $3,8,9,12,16,17,21,23$, $29,34,37,44$, and 48 ; (b) health responsibility was scored by summing items $2,7,15,20,28,32,33,42,43$, and $47 ;$ (c) exercise subscale was computed by summing items $4,13,22,30$, and 38 ; (d) nutrition was calculated by summing the responses from items $1,5,14,19,26$, and 35 ; (e) the interpersonal support subscale was derived by summing items $10,18,24,25,31,39$, and $47 ;$ and (f) the stress management subscale was obtained by summing 
responses from items $6,11,27,36,40,41$, and 45 (see Appendix D). The summed scores were averaged, as recommended by Walker, Sechrist, and Pender (1987), to allow for meaningful comparison of scores across subscales of the surveys.

\section{Data Analysis}

Mean, standard deviation, and range for the subscales and the total scores of both the LHCS and HPLP was used to describe the group responses. Means, standard deviation, and range for responses were compiled in table 2 for health concepts and table 3 for health promoting behaviors. In each case, the higher the mean score, the greater the degree of favorable responses among participants for each subscale. Mean subscale scores for clinical health, role performance health, adaptive health, and eudaimonistic health (Table 2) ranged from 4.23 to 4.57 . The least homogeneous scores were in the clinical health subscale with a standard deviation of 1.11 .

Mean subscale scores for exercise, nutrition, health responsibility, stress management, interpersonal support, and self-actualization (Table 3) ranged from 2.09 to 3.16 . The least homogeneous scores were in the exercise subscale with a standard deviation of 0.80 . Wilcoxon matched-pair testing was done to examine the data for the presence of relationships between the dependent and independent variables. There were no statistically significant 
Table 2

Data Analysis of Responses to Health Concepts

\begin{tabular}{lccc}
\hline \multicolumn{1}{c}{ Concepts (LHCS) } & $\mathrm{N}$ & Mean & Stdev \\
\hline Clinical health & 70 & 4.23 & 1.11 \\
Role performance ffunctional health & 70 & 4.45 & 0.90 \\
Adaptive health & 70 & 4.57 & 0.82 \\
Eudaimonistic health & 70 & 4.40 & 0.76 \\
Total & 70 & 4.40 & 0.65 \\
\hline
\end{tabular}

Table 3

Data Analysis of Responses to Health Promoting Behaviors

\begin{tabular}{lccc}
\hline \multicolumn{1}{c}{ Behaviors (HPLP) } & $\mathrm{N}$ & Mean & Stdev \\
\hline Self-actualization & 70 & 3.16 & 0.58 \\
Health responsibility & 70 & 2.09 & 0.52 \\
Exercise & 70 & 2.28 & 0.80 \\
irutrition & 70 & 2.32 & 0.71 \\
Interpersonal support & 70 & 3.05 & 0.52 \\
Stress management & 70 & 2.60 & 0.57 \\
Totals & 70 & 2.66 & 0.40 \\
\hline
\end{tabular}

Note. Higher scores on tables 2 and 3 denote higher health concepts or values on all subscales for LHCS and HPLP. 
differences found among the means between the independent and dependent variable scores. The profile of subscale mean scores varied among student participants. The group means for health concepts scored higher than the group means for health promoting behaviors suggesting that although the group understood what health was, they have not necessarily engaged in some of the health promoting behaviors at the time of this research.

Group relationships were done to determine if any statistically significant results of the data existed between the independent variables (health concepts) and the dependent variables (health behaviors) of the two health related surveys. The data were entered into Minitab, a statistical software computer program (Ryan, Joiner, \& Ryan, 1992), and analyzed using correlation coefficient statistics (Table 4) that computed the relationship between the columns of data of the independent and dependent variables (subscales). When the cumulative totals for the LHCS and HPLP were correlated the resulting spearman's rho was .008 (see Table 4). This result indicated that there was not a statistically significant relationship between the individual's concept or definition of health and the health promoting behaviors they engaged in. Although the results were not statistically significant there was a weak positive correlation between the cumulative totals for LHCS and HPLP. 
Table 4

Intercorrelations Among the Variables (Subscales) of Health Concepts (LHCS) and Health Promoting Behaviors (HPLP)

\begin{tabular}{lrrrrr}
\hline & CLHE & ROLE & ADHE & EUD & SUM \\
SA & .008 & .096 & .224 & .170 & .135 \\
HR & -.270 & -.076 & .094 & .016 & -.093 \\
EX & -.246 & -.001 & .030 & .056 & -.058 \\
NUT & -.103 & -.183 & .080 & .010 & -.062 \\
IS & .132 & .016 & .176 & .019 & .107 \\
SM & .018 & -.073 & .199 & .107 & .084 \\
TOT & -.071 & -.034 & .178 & .061 & .008 \\
\hline
\end{tabular}

Note. Key to identify above health behaviors.

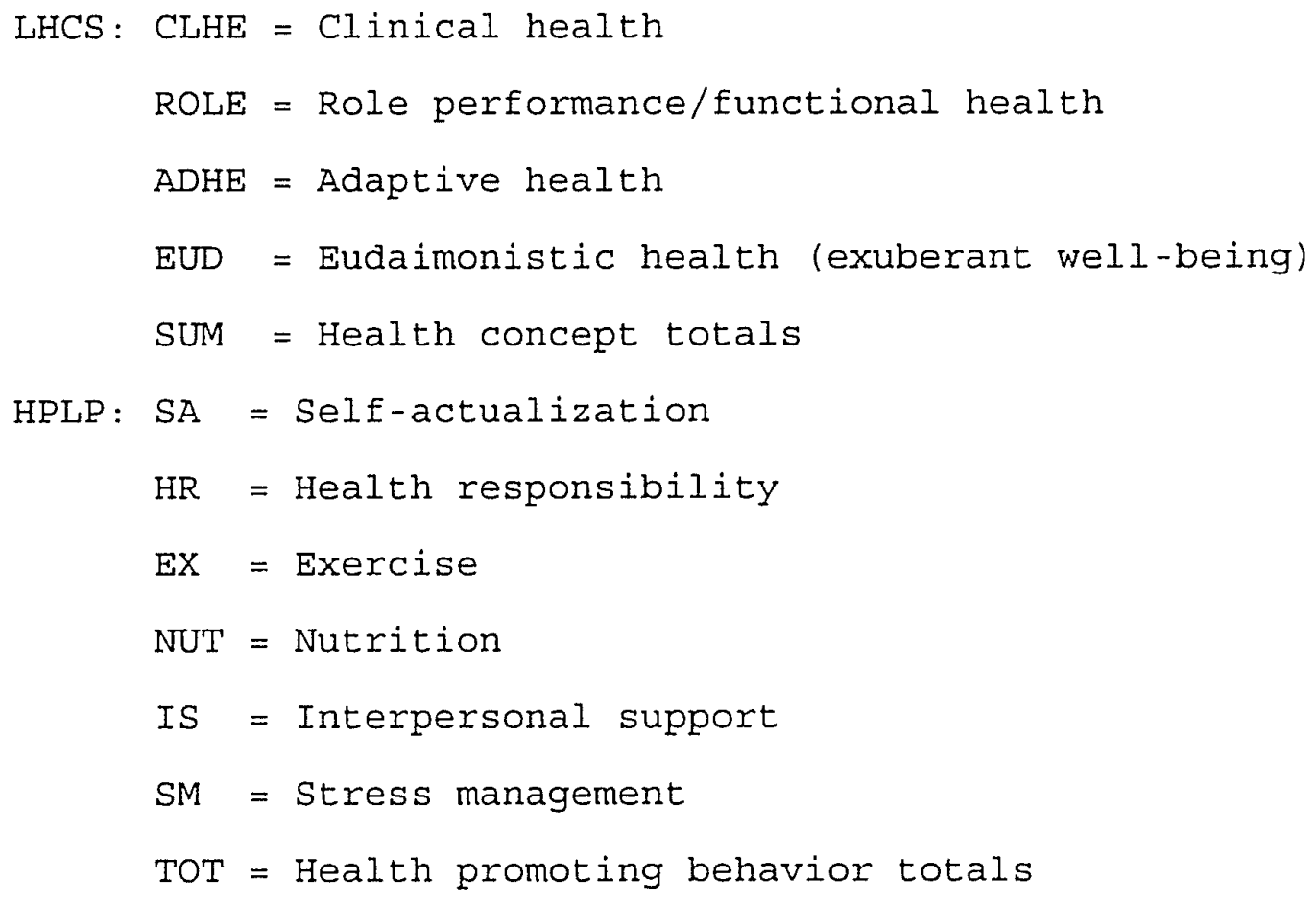


The strongest positive correlation existed between adaptive health and self-actualization $(\underline{r}=.22)$ (see Table 4) suggesting that as individuals adapted to their health needs in a positive manner, their outlook on life improved. In contrast, the strongest negative correlation $(\underline{r}=-.27)$ (see Table 4) between clinical health and health responsibility suggested that when there was an absence of disease or illness then taking responsibility for one's health decreased. Correlations between health behaviors and health concepts were consistently weak, suggesting these two domains were independent of each other.

The low magnitude of the correlation suggested each subscale represents a distinct health dimension not related to another health dimension. The modifying factors of demographics and biological characteristics, and cues to action from the HPM were not considered when the relationships between concepts and promoting behaviors were measured. The weak correlation of relationships can not be fully supported nor contradicted using the HPM theory.

In summary, health concepts and health promoting behaviors were compared to determine what relationship existed among the subscales. Findings were reported in (a) percentages for the demographic data, (b) means and standard deviation for group responses of LHCS and HPLP, and (c) correlation coefficient results for relationships between the variables. 


\section{Chapter 5 \\ DISCUSSION}

Summary of study

This descriptive study, utilizing Pender's Health Promotion Model (HPM), gathered data from 70 students via self-reported surveys that measured health concepts and health promoting lifestyle behaviors. This chapter summarizes the study and presents the scope, limitations and assumptions of the study, plus the conclusions and recommendations reached by the investigator.

Pender's Health Promoting Behavior Model served as the conceptual framework for this study. Pender (1987) believed that an individual's level of health behaviors were directly proportional to one's level of health perceptions. The purpose of this study was to explore the relationship between 4 aspects of health concepts:
(1) clinical health
(2) role performance/functional health, (3) adaptive health, and (4) exuberant well-being; and 6 aspects of health promoting lifestyle behaviors:

(1) self actualization, (2) health responsibility, (3) nutrition, (4) exercise, (5) stress management, and (6) interpersonal support among a sample of 70 community college students. The HPM conceptual framework provided an active, dynamic, and optimistic explanation of health promoting behaviors. Many research questions, however, 
still remain unanswered because of limited research done that would afford a better understanding of the Health Promotion Model variables.

\section{Scope of the study}

Two important issues were addressed in this study. The first issue concerned the lack of descriptive information about health perceptions of college students. The second issue concerned the relationship between health concepts and health promoting behaviors in these individuals. The data in the study showed that health concepts and health behaviors were multidimensional in nature and not necessarily related to one another.

The results of the study found that there were positive and negative correlations, or relationships, between the subscales of health concepts and health promoting behaviors. The correlation coefficient between health concepts and health promoting behaviors were consistently weak (Table 4) suggesting the two domains of health were independent of each other. Interestingly, it was noted that students with higher health concept scores had higher health behavior scores. Students with lower health concept scores had lower health behavior scores, whereas other students differed across subscales or had one subscale which stood out from the others.

However, there were no statistically significant differences in means between health concepts and health 
promoting behaviors indicating that a definiton of health could not be shown to contribute to students engaging in health promoting behaviors. These findings were consistent with Felton and Parsons' study (Sachs, 1991). Felton and Parsons randomly selected 593 students who lived on campus. The majority of students were white (84\%), and female (46\%). This study was considerably smaller with only 70 participants who did not live on campus. The majority of participants in this study were white (49\%), and female $(57 \%)$.

Felton and Parsons gathered information over a two month period using four survey questionnaires. This study collected data cver a two week period using two of the four surveys. Felton and Parsons identified subgroups in need of intervention, whereas this study did not. However, Felton and Parsons concluded that the definition of health did not contribute to health promoting behavior, which was similar to the findings of this study.

Mean scores for subscales were different than those obtained by other researchers (Laffrey, 1986; Pender, 1987) suggesting that the sample may be somewhat atypical. Clinical health, role performance health, exercise, stress management, self actualization, and interpersonal support showed higher scores in this study. Additionally, lower scores were found in adaptive health, eudaimonistic health, total LHCS, health responsibility, and nutrition. 
Assumptions of the Study

The HPM conceptual framework assumed that specific types of behaviors related to one another. This assumption may not always be correct. Certain variables (subscales) may not impact the person's decision to engage in changes related to an activity behavior (Palank, 1991). This study assumed that (1) the more that an individual positively conceptualized their health, the more likely that person would engage in health promoting lifestyle behaviors, and (2) the participants who used the student health center would be more likely to engage in positive health behaviors. These assumptions were not supported by the descriptive statistical measures. The relationship between health concepts and health promoting behaviors in the study showed a weak relationship indicating that although participants understood the need to maintain health promoting lifestyle behaviors they did not necessarily follow health promoting activities to enhance their health.

\section{Limitations of the Study}

The limitations of this study were two-fold (a) a convenience sample was used to optimize sample size and (b) data were obtained through self-report. Sample selection was based on the convenience of the volunteer participants and the participants were knowledgeable about the health center. However, one needs to consider sample size, selection, and research design when looking at the 
data from the study. Because the sample in this study was limited to community college students, caution must be exercised in generalizing to other college or university students.

Characteristics of the sample such as voluntary participation and collection of the data at a single site may have limited the external validity of the findings. Additionally, some unmeasured factors that influence lifestyle, such as peer pressure, juggling study schedules, and employment demands may have affected student responses. Socioeconomic, environmental risks, and sophisticated advertising factors are powerful determinants of health, but individuals have limited control over them which can cause limitations in any research (Squyres, 1985). Some individuals may not have understood what health means and may have answered questions in a manner they thought the researcher wanted to hear, as data were collected through self report. Another factor may have been that those who chose to respond were different from those who chose not to respond to the self-administered questionnaire either in beliefs, knowledge, attitude, or interest in health promotion.

\section{Conclusions}

This study attempted to demonstrate a relationship between health concepts and health promoting lifestyle behaviors. Findings of the present study provided only 
weak support for a relationship between the independent and dependent variables in a sample of community college students in a small rural Northern California community college. The results from the study concluded that although the participants understood what the term health meant, they have not necessarily engaged in many of the health promoting lifestyle behaviors for their health. The study also concluded that one's conception of health may be a more significant factor for participation in lifestyle behaviors to promote their health.

The information obtained from the health concept survey and the health promoting behavior survey were intended to increase information about college students' health behaviors that could be utilized for planning improved health programs at the participating community college. Health surveys are one way to initiate health behavior changes and to motivate individuals to make health promoting lifestyle changes (Browne et al., 1988). One aspect of using health surveys that has not been made explicit was that the health conception and health promoting behavior surveys may have provided an impetus to help students change health behaviors. The use of health surveys as tools to motivate individuals for health change merits further investigation, and should not be overlooked (Browne et al., 1988).

Although most people would agree that health promotion 
is desirable, when the opportunity for action is presented many people may lack motivation or have personal confusion over the level of committment needed for participation or choose a lower level of participation (Wynd, 1990). The study showed both positive and negative correlations between health concepts and health promoting behaviors, and these results can be useful when trying to plan strategies for individual lifestyle areas of college students. The study did not address cues to action or modifying factors which may have played a strong role in resultant concept and behavior responses of the participants.

According to Patrick (1992), "current estimates are that as many as $30 \%$ of college students lack any form of health insurance" (p.501). The escalating costs of medical care have created circumstances that effectively denied youth to access even simple health care (Patrick, 1992). As more uninsured students utilize the student health services, health costs will escalate causing increased needed reimbursement costs that have been relatively low (Patrick, 1992). The implication for student health services has been that there will be fewer services that cost more money. With 28 percent of the sample not having medical insurance, student health services would be impacted as more students use the services. These college students would need more complicated health interventions. College students are at a time in their lives when positive 
changes in behaviors would have long term positive effects on their health that would eventually reduce the need for intensive medical care, and ultimately lower health care costs.

College health nurses are in a unique position to act as leaders and role models in promoting the health of their students. By acquiring knowledge about the dimensions of health, the college health nurse can design and implement strategies for behavioral changes. The college health nurse may need to focus on cues to action or modifying factors to induce individuals to participate in health practices. However, the college health nurse can contribute to (a) the enhancement and maintenance of the students' health, and (b) the development of nursing science.

\section{Recommendations}

The following recommendations for the future are made based on the findings of this study:

1. The study group should be limited to one age, sex, or ethnic group category in order to insure one constant controlled variable among the participants.

2. A test-retest study should be done to compare the group to determine stability of the attitudes being measured and to measure changes in health promoting behavior lifestyle as a result of interventions of a health promotion education program. 
3. A comparison with another group of participants who were not necessarily aware of the health center and health responsibilities could be done on the campus away from the health center.

4. Community colleges have many students over 50 years of age, thus the recommendation is to include this group in a study to determine the needs of all students and plan programs accordingly to meet their health needs on campus.

In summary, the findings of the study contribute to nursing research and practice. Although generalization of the study is a problem, the study findings provide additional information that the Health Promotion Model is useful for providing a conceptual framework to understanding health promoting lifestyles and for guiding research related to health promoting activities in college students. The findings in this study provide direct support for adding knowledge to the nature of the relationships discussed in Pender's Health Promotion Model between the individual's perception of four health conceptions and the practices of six health promotion activities in a sample of community college students. 
REFERENCES 
References

Allan, J. (1987). Identification of health risks in a young adult population. Journal of Community Health Nursing, 4 (4), $223-233$.

American College Health Association. (1992). Healthy campus 2000: Building the foundation. Baltimore, MD: Author. American Nurses Association. (1990). A statement on the scope of college health nursing practice. Kansas City, MO: Author.

Boyton, R. (1962). Historical development of college health services. Student Medicine, 10 (3), 294-30.

Browne, G., Byrne, C., Roberts, J., Streiner, D., Fitch, M., Corey, P., \& Arpin, K. (1988). The meaning of illness questionnaire: Reliability and validity. Nursing Research, 37, 368-373.

Burns, W. (1992). Alcohol on the college campus. In $\mathrm{H}$. Wallace, K. Patrick, G. Parcel, \& J. Igoe (Eds.), Principles and practices of student health: Vol 3 . College health (pp. 589-601). Oakland, CA: Third Party Publishing Co.

Delene, L. (1992). Relationship marketing and service quality. Journal of American College Health, 40 (6), 265.

Doerr, B.\& Hutchins, E. (1981). Health risk appraisal: Process, problems, and prospects for nursing practice and research. Nursing Research, 30, 299-306. 
DuBrey, R. (1982). Promoting wellness in nursing:

A step-by-step approach in patient education. St Louis, MO: The C. V. Mosby Co.

Duffy, M. (1993). Determinants of health-promoting

Iifestyles in older persons. Image, 25 (1), 23-28.

Fleury, J. (1992). The application of motivational theory

to cardiovascular risk reduction. Image, 24 (3), $229-239$.

Frank-Stromberg, M., Pender, N., Walker, S., \& Sechrist, K. (1990). Determinants of health promoting lifestyle in ambulatory cancer patients. Social Science \& Medicine, 31 (10), 1159-1168.

Gale, B. \& Clark, H. (1986). Well women's clinic: A health promotion program. Journal of Community Health Nursing, 3. (2), 75-85.

Green, L., Kreuter, M., \& Deeds. (1980). Health education planning: A diagnostic approach. Palo Alto, CA: Mayfield Publishing Co.

Halfman, M., \& Hojacki, L. (1981). Exercise and maintainence. Topics in Clinical Nursing, $7,1-8$. Health Services Association of California Community Colleges. (1992, February). Summary to resolve to lobby for increased student health fees. Monterey, CA: Author. Issac, S. \& Michael, W. (1985). Handbook in Research and Evaluation (p. 193). San Diego, CA: Editors. 
Jaeger, R. (1990). Statistics: A spectator sport, (2nd ed.). Newbury Park, CA: SAGE Publications.

Johnson, R. (1988). Elements of nonparametric statistics. Elementary statistics: Fifth edition. Boston, MA: PWS-KENT Publishing.

Jones, D., Harel, Y., \& Levinson, R. (1992). Living arrangements, knowledge of health risks, and stress as determinants of health-risk behavior among college students. Journal of American College Health, 41 (2), 43-48

Kerr, M. \& Ritchey, D. (1990). Health promoting life styles of English-speaking and Spanish-speaking Mexican American migrant farm workers. Public Health Nursing, 7 , $80-87$.

Klotz, A. (1974). A new model for college student health services. Journal National Association student Personnel 11 (4), 6-9.

Kurtzman, F. \& Yager, J. (1992). Eating disorders and the college population. In $\mathrm{H}$. Wallace, K. Patrick, G. Parcel, \& J. Igoe (Eds.), Principles and practices of student health: Vol. 3. College health (pp. 706-713). Oakland, CA: Third Party Publishing Co. Laffrey, S. (1986). Development of a health conception scale. Research in Nursing and Health, 9, 107-113. 
Laffrey, S. (1985). Health behavior choice as related to self actualization and health conceptions. Western Journal Nursing Research, I, 279-295.

Lappin, M. (1992). Non-traditional students in colleges and universities. In H. Wallace, K. Patrick, G. Parcel, \& J. Igoe (Eds.), principles and practices of student health: Vol 3. College health (pp. 795-797). Oakland, CA: Third Party Publishing Co.

Lauzon, R. (1977). Epidemiological approach to health promotion. Canadian Journal of Public Health, 68, $311-317$.

LoBiondo-Wood, G. \& Haber, J. (1990). Nursing research: Methods, critical appraisal, and utilization, (2nd ed.). St. Louis, MO: The C.V. Mosby Co.

Lovato, C. (1992). Tobacco use among college students. In H. Wallace, K. Patrick, G. Parcel, \& J. Igoe (Eds.), Principles and practices of student health: Vol 3 . College health (pp. 602-612). Oakland, CA: Third Party Publishing Co.

Oleckno, W. \& Blacconiere, M. (1990). Risk taking behaviors and other correlates of seat belt use among university students. The Society of Public Health, 104, 155-164. Paillard, M. \& Nowak, K. (1985). Use exercise to help older adults. Journal of Gerontological Nursing, 11 (7), $36-39$. 
Palank, C. (1991). Determinants of health promotive behavior: A review of current research. Nursing Clinics of North America, 26 (4), 815-832.

Patrick, K. (1992). The history and current status of college health. In $\mathrm{H}$. Wallace, K. Patrick, G. Parcel, \& J. Igoe (Eds.), Principles and practices of student health: Vol 3. College health (pp. 501-512). Oakland, CA: Third Party publishing Co.

Pender, N. (1987). Health promotion in nursing practice, (2nd ed.). Norwalk, CT: Appleton \& Lange Publishing Co. Pender, N., walker, S., Sechrist, K., \& Frank-Stromberg, M. (1990). Predicting health promoting lifestyles in the workplace. Nursing Research, 39 (6), 326-332.

Peplau, H. (1986). The nurse as counselor. Journal of American College Health Association, 34, 11-14.

Redman, B. (1984). The process of patient teaching in nursing, (4th ed.). St. Louis, MO: The C. V. Mosby Co. Ryan, B., Joiner, B., \& Ryan, T. (1992). Minitab handbook, (2nd ed.). Boston, MA: PWS-KENT Publishing Co. Sachs, B. (1991). Sigma Theta Tau supports health promotion research. Reflections, $17(2 / 3), 4-6$.

Scandrett, S., \& Uecher, S. (1985). Relaxation training. In G.M. Bulechak \& J.C. Mckloskey (Eds.), Nursing intervention: Treatment for nursing diagnosis (pp. 22-48). Philadelphia, PA: Saunders Publishing Co. 
Selye, H. (1977). Introduction. In D. Wheatley (Ed.), Stress and the heart $(p .1)$. New York, NY: Raven Press. Sharp, N. (1991). Healthy people 2000: National health promotion and disease prevention. Nursing Management, $\underline{22}$ (8), 10-11.

Sloane, B. \& Zimmer, C. (1992). Health education and health promotion on campus. In H. Wallace, K. Patrick, G. Parcel, \& J. Igoe (Eds.), Principles and practices of student health: Vol 3. College health (p. 539). Oakland, CA: Third Party Publishing Co.

Smith, M. (1990). Nursing's unique focus on health promotion. Nursing Science Quarterly, 3 (3), 105-6. Speake, D. (1987). Health promotion activity in the well elderly. Health Values, 11, 25-30.

Squyres, W. (1985). Risk assessment and health improvement. Patient education and health promotion in medical care. Palo Alto, CA: Mayfield Publishing Co. Standhope, M. \& Lancaster, J. (1984). Community health nursing: Process and practice for promoting health. st. Louis, MO: The C. V. Mosby Co. U.S. Department of Health, Education, and Welfare, Public Health Service. (1990). Healthy people: The surgeon general's report on health promotion and disease prevention. Pub. No. 79-55071. 
Volden, C., Langemo, D., Adamson, M., \& Oechsle, L. (1990). The relationship of age, gender, \& exercise practices to measures of health, lifestyle, \& self esteem. Applied Nursing Research, $\underline{3}$ (1), 20-26. Walker, S., Sechrist, K., \& Pender, N. (1987). The health promoting lifestyle profile: Development and psychometric characteristics. Nursing Research, $\underline{36}$ (2), 76-81.

Walker, S., Volkan, K., Sechrist, K., \& Pender, N. (1988). Health promoting life styles of older adults: Comparison with young and middle-aged adults. Advances in Nursing Science, $11,76-90$.

Wallace, H., Patrick, K., Parcel, G., \& Igoe, J. (1992). Principles and practice of student health: Vol 3. College health. Oakland, CA: Third Party Publishing Co. Waller, P., Crow, C., Sands, D., \& Becker, H. (1988). Health related attitudes and health promoting behaviors: Differences between health fair attendees and a community comparison group. American Journal Health Promotion, $3,17-24$. Weitzel, M. (1989). A test of the health promotion model with blue collar workers. Nursing Research, 38, 99-102. Whitaker, L. (1989). The bulemic college student: Evaluation, treatment, and prevention. Journal of College Student Psychotherapy, $\underline{3}$ (4), 69-73. 
Wynd, C. (1990). Analysis of a power theory for health promotion activities. Applied Nursing Research, 3 (3), $118-127$.

Zapka, J. \& Love, M. (1985). College health services: Setting for community, and individual change.

Family and Community Health: the Journal of Health

Promotion and Maintenance, 8 (1), 18-34. 


\section{APPENDIX A}

Permission from SJSU Human Subjects in Research 
Olfice of the Academic Vice President - Assoclate Acadomic Vice Presidenl * Graduato Studios and Research

One Washington Square * San José. California 95192-0025 • 408/924-2480

To: Brenda Laird

2132 Casa Grande Place

Benicia, CA 94510

From: serena $w$. stanford tereme th thanfore
AAVP, Graduate studies and Research

Date: December 2, 1992

The Human Subjects-Institutional Review Board has reviewed and approved your request for exemption from Human Subjects Review for the proposed study entitled:

"The relationship between reported health concepts and health promotive behaviors in college students"

Provided that there are no changes in the procedure proposed, you may proceed with this study without further review by the Human Subjects-Institutional Review Board. You must notify the Human Subjects-Institutional Review Board of any changes in the subject population or procedure for this study

I do caution you, however, that Federal and state statutes and University policy require investigators conducting research under exempt categories to be knowledgeable of and comply with Federal and state regulations for the protection of human subjects in research. This includes providing necessary information to enable people to make an informed decision regarding participation in your study. Further, whenever people participate in your research as human subjects, they should be appropriately protected from risk. This includes the protection of the confidentiality of all data that may be collected from the subjects. If at any time a subject becomes injured or complains of injury, you must notify Dr. Serena stanford immediately. Injury includes but is not limited to bodily harm, psychological trauma and release of potentially damaging personal information.

Please also be advised when people participate in your research as human subjects, each subject needs to be fully informed and aware that their participation in your research project is voluntary, and that he or she may withdraw from the project at any time. Eurther, a subject's participation, refusal to participate or withdrawal will not affect any services the subject is receiving or will receive at the institution in which the research is being conducted.

If you have questions, please contact me at 408-924-2480. 
APPENDIX B

Permission to Conduct Study 
September 14, 1992

Human Subjects Review Committee

San Jose State University

San Jose, California 95192

To whom it may concern:

Brenda Laird, a graduate student at San Jose State University, has permission to use the Health Promoting Lifestyle Profile and the Health Conception Scale with student participants from Solano Community College for her masters thesis research project. She will assure participants that all data collected will be kept anonymous and confidential.

Sincerely,

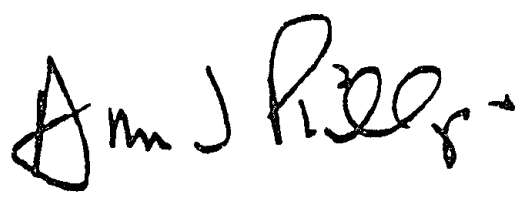

Armond Phillips

Dean of Academic Affairs

Solano Community College 


\section{APPENDIX C}

Laffrey Health Conception Scale

Instrument and Permission to Use 
SCHOOL OF NURSING

THE UNIVERSITY OF TEXAS AT AUSTIN

1700 Red River Aussin, Toxas $78701-1499 \cdot(512) 471-7311$

$F A X(512) 471-4910$

June 1, 1992

Brenda Laind

2132 çasa Grande

Benicia, CA 94510

Dear Lt. Commander Mullin:

Thank you for your interest in the Laffrey Health Conception Scale. Enclosed is a copy of the most recent form of the LHCS with scoring information. Initial support for content and construct validity and internal consistency are described in the enclosed "Overview of the LHCS." Work on validity and reliability establishment is continuing. To assist in this process, I would appreciate receiving the following from you should you use the instrument:

1. Ranges, means and standard deviations of the subscores and total LHCS scores for your population

2. Demographic information for your population (i.e. age, sex, race,ethnicity and description of population such as orthopedic, cardiovascular inpatients, etc.)

3. Any reliability estimates that you do as part of your study

4. A summary of your results

These data will assist in the further development of the validity and reliability of the LHCS and also contribute to the development of a normative data base. Data which you provide me will be used for this purpose only.

I hope you find the LHCS useful in your research. Please contact me with any questions or comments you have about the scale and its use in your research.

Sincerely,

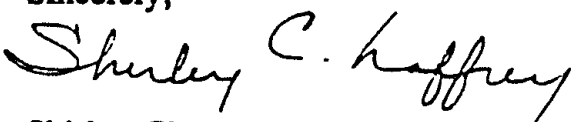

Shiriey Cloutier Laffrey, Ph.D., R.N.

Associate Professor

Enc. 


\section{PLEASE NOTE}

Copyrighted materials in this document have not been filmed at the request of the author. They are available for consultation, however, in the author's university 1ibrary.

$68-69$

University Microfilms International 


\title{
APPENDIX D
}

Health Promoting Lifestyle Profile

\author{
Instrument and Permission to Use
}




\section{From the desk of:}

\section{NOLA J. PENDER}

$8 / 11 / 92$

Brenda:

Please excuse the delay in getting HPLP

materials to you. I have not been at the

Northern Illinois University for two years

and they forward my mail only every $2-3$ months

when it accumulates. I hope these materials

are helpful. You have my permission to use the

instrument.

Cordially,

Nola Pender 
HEALTH-PRO:OTING LIFESTYLE PROFILE

Dear Colleague:

We are pleased to reply to your request for information about our HealthPromoting Lifestyle Profile. In order to respond promptly to the large volume of correspondence we receive, we have found it necessary to prepare this standard letter containing information that is commonly sought. We hope that you will feel free to write or call as necessary to obtain any further information that you may need.

The Health-Promoting Lifestyle Profile measures health-promoting behavior, conceptualized as a multidimensional pattern of self-initiated actions and perceptions that serve to maintain or enhance the level of wellness, self. actualization and fulfillment of the individual. The 48-item summated behavior rating scale employs a 4-point response format to measure the frequency of selfreported health-promoting behaviors in the domains of self-actualization, health responsibility, exercise, nutrition, interpersonal support and stress management. It was developed for use in research within the framework of the Health Promotion Model (Pender, 1987), but has subsequently been employed for a variety of other purposes as well. The development and psychometric evaluation of the English language versions were described by Walker, Sechrist and Pender (1987) and scores among the initial study sample were reported by Walker, Volkan, Sechrist and Pender (1988). The translation and psychometric evaluation of the Spanish language version as well as scores among a Hispanic sample were reported by Walker, Kerr, Pender and Sechrist (1990).

Copyright of both English and Spanish language versions of the instrument is held by Susan Noble Walker, EdD, RN, Karen R. Sechrist, PhD, RN, FAAN and Nola $J$. Pender, PhD, RN, FAAN. You have our permission to copy and use the enclosed Health-Promoting Lifestyle Profile for non-commercial data collection purposes such as research or evaluation projects provided that content is not altered in any way and the copyright/permission statement at the end is retained. The instrument also may be reproduced in the appendix of a thesis, dissertation or research grant proposal without further permission. Reproduction for any other purpose, including the publication of study results, is prohibited without specific permission from the authors.

There is no charge for such auchorized use, but we would appreciate receiving notification of your intent to use the instrument and a report of your completed study/project for our files. It is particularly useful to know of any publications reporting use of the instrument so that we can maintain an accurate complete listing. To facilitate record keeping, all information should be sent to:

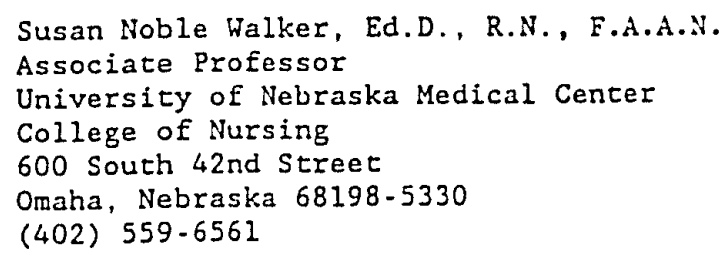

We thank you for your interest in using the Health-Promoting Lifestyle Profile and wish you much success with your efforts.

Sincerely,

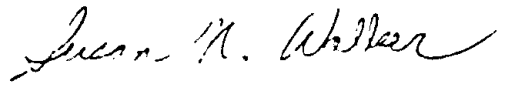


PLEASE NOTE

\begin{abstract}
Copyrighted materials in this document have not been filmed at the request of the author. They are available for consultation, however, in the author's university 1 ibrary.
\end{abstract}

$73-74$

University Microfilms International 
APPENDIX E

Student Demographic Profile 
STUDENT DEMOGRAPHIC PROFILE FOR NURSING RESEARCH PAPER

Please circle only one number in each category

SEX:
1. Female
2. Male

AGE:

1. Under 21 yrs.

2. 21 - 30 yrs.

3. 31 - 40 yrs.

4. $41-50$ yrs.

5. 51 - 60 yrs.

6. $61-70$ yrs.

7. Over 70 yrs.

ETHNIC GROUP/RACE:

1. Hispanic/Latino

2. Black/African-American

3. American Indian/Alaskan

4. Asian/Pacific Islander

5. Caucasian/White

6. Other

(please specify)

STUDENT STATUS:

1. Full time (12+ credits)

2. Part time (1-11 credits) COLLEGE MAJOR: (primary focus)

(please specify)

MARITAL STATUS AT THIS TIME:

1. Single

2. Married

3. Widowed

4. Divorced

5. Separated

EMPLOYMENT STATUS:

1. Employed full time

2. Employed part time

3. Unemployed

4. Retired MEDICAL INSURANCE:

1. Kaiser

2. Military

3. Private

4. Medi-Cal/Medicare

5. No Insurance

(All data will be reported as group information only). 


\section{APPENDIX F}

Participant Cover Letter and Consent Form 
consent Form

You are invited to participate in a research study that will explore the relationship between health concepts and health promotion behaviors with college students. This study is being conducted by Brenda Laird,R.N., as a thesis investigation in partial fulfillment of the requirements for a Master of Science degree in Nursing at San Jose State University.

If you consent to participate in this stlidy, you will be given two written questionnaires to complete. Your participation is entirely voluntary, and you may withdraw from the study at any time.

There will not be any direct benefit to you for participating in this study, but your participation will help to evaluate any changes that may occur in the complex relationships between the importance of health and lifestyle behaviors in college students.

There should not be any risk to you for participating in this research nor will you be denied service from SJSU or solano Community college, of any kind, to which you are otherwise entitled, if you chose not to participate in this study.

All information will be kept confidential, and the results will be completely anonymous. If you would like a copy of the results of the study, they will be made available to you at your request.

Please feel free to ask me any questions you may have about the study. You may contact me at (707) 747-1724, or Dr. Elizabeth Dietz at (408) 924-3172, my thesis advisor. Questions or complaints about research, subjects' rights, or research-related injury may be presented to Serena stanford, PhD., Associate Vice President of Graduate and Research, at (408) $924-2480$.

You are making a decision whether or not to participate. Your signature indicates that you have decided to participate, having read the information above.

Signature of participant

Date

Signature of investigator

Date 